\title{
REGIONAL PULMONARY BLOOD FLOW IN PATIENTS WITH CIRCULATORY SHUNTS
}

\author{
BY \\ C. T. DOLLERY, J. B. WEST, D. E. L. WILCKEN, J. F. GOODWIN, \\ AND P. HUGH-JONES
}

From the Department of Medicine, Postgraduate Medical School of London and Hammersmith Hospital

Received October 19, 1960

Carbon dioxide labelled with oxygen-15 can be used to compare the blood flow in different regions of the lung. Results obtained with this technique in normal subjects at rest with the chest upright show that there is a much higher perfusion per unit of alveolar volume in the lower zone than in the upper zone. On moderate exercise the flow increases in both zones but the lower zone blood flow remains relatively greater than the upper zone (West and Dollery, 1960). Patients with mitral stenosis differ from the normal in that the moderately severe cases show almost equal perfusion in upper and lower zones and the severe cases have a higher perfusion in the upper than the lower zone (Dollery and West, 1960). This inversion of the normal distribution of blood flow has been observed also in patients with left ventricular failure and pulmonary œdema (Dollery and West, in preparation). The distribution of blood flow in normal subjects probably depends upon the effect of gravity on the low perfusion pressures in the pulmonary circulation.

Heart disease may reduce the normal difference in the upper and lower zone clearance rates. To investigate this problem further we have studied a group of patients with congenital shunts between the left and right sides of the heart. These patients have a great variety of pulmonary pressures and flows. This study was made with a specially selected group of such patients in whom complete hæmodynamic investigations had been performed. The results demonstrate differences between the flow patterns in various disorders of the pulmonary circulation and throw some light on the factors that influence the partition of blood flow between different regions of the lung.

\section{Methods}

Oxygen-15, which has a half-life of only two minutes, was produced continuously in the Medical Research Council cyclotron by deuteron bombardment of nitrogen molecules. After purification the gas was piped to an adjoining laboratory where it was either diluted with air for immediate use as oxygen or converted before dilution to carbon monoxide or carbon dioxide. The radioactivity of the final diluted mixture was monitored continuously in a re-entrant ionization chamber. Usually two breaths of each of these gases were given so that the total number of breaths taken was six. Here we shall only consider results obtained using carbon dioxide because this gas has been shown to be the best for measuring regional blood flow (West et al. (in press)). The radiation dose from this number of breaths has been calculated not to exceed 350 millirads.

During the test the patient sat upright in a chair with neck and arm rests to minimize movement. The patient breathed from a low deadspace respiratory valve box, and at the end of a normal expiration inhaled rapidly to empty a bag containing $900 \mathrm{ml}$. of air containing a trace of the chosen radioactive gas. When the bag was empty the patient held his breath for ten to fifteen seconds and 
then resumed normal breathing. The inspired radioactivity was detected by pairs of crystal scintillation counters aligned in front of and behind the chest. Thus the function of cores of lung tissue between the counters could be compared. One pair of counters was placed over the left second rib 3 inches from the mid line and the other over the right lung 4 inches lower down in the adult patients and 3 to $3 \frac{1}{2}$ inches lower in the children. These positions were chosen to allow simultaneous measurement of the clearance rate of the radioactive gas in the upper and lower zones. It was necessary to avoid the left lower zone because blood carrying radioactivity accumulating in the heart sometimes interfered with the clearance curve. The signals from the scintillation counters were fed through amplifiers to ratemeters and displayed on pen-recorders.

The clearance rate of each radioactive gas was calculated from the rate of fall of counting rate during the breath-holding after allowance had been made for background radiation and radioactive decay. Carbon dioxide is removed exponentially and the clearance rate has been expressed as the percentage per second of the instantaneous activity.

Interpretations. Carbon dioxide labelled with oxygen-15 is taken up in the lung very rapidly. This may seem incongruous because a net excretion of carbon dioxide takes place. In fact, when blood passes along the pulmonary capillary a rapid movement of carbon dioxide takes place between blood and alveolus in both directions. The net transfer depends on the ratio of the partial pressures so that more carbon dioxide enters the alveolus than goes in the reverse direction into blood. However, only the latter is labelled. Bicarbonate is formed in the blood and the labelled bicarbonate exchanges its oxygen-15 with oxygen-16 in water (Dollery and West, $1960 \mathrm{a}$ ) and as a result the partial pressure of the labelled carbon dioxide in the blood is exceedingly small. This process ensures that the uptake of the isotope into blood is very rapid. The clearance curves show the rate of removal of the labelled blood from the counting field and are therefore a measure of the blood flow through the region of lung between the counters.

Normal Values. Measurements that were made in five young normal subjects at the same positions as in this series of patients (West et al., 1960) showed that the mean carbon dioxide clearance rate was 4.8 per cent per second (standard error $2 \cdot 1$ ) at the level of the second rib and 23.5 per cent per second (standard error $1 \cdot 7) 4$ inches $(10 \mathrm{~cm}$.) lower over the right lung. The individual results from these five subjects have been used in Fig. 9.

\section{The Patients}

A representative group of 15 patients with cardiac shunts, with and without pulmonary hypertension, was studied. There were seven patients with ventricular septal defect, four with atrial septal defect, and four with patent ductus arteriosus. The diagnosis in each case was made on clinical evidence, including electrocardiography and radiography, and confirmed by right heart catheterization. Dye dilution curves provided additional confirmation of the presence of a leftto-right shunt and afforded accurate localization of the site of a right-to-left shunt when this was present. Angiocardiography was carried out in all but three patients. Three patients with ventricular septal defects had associated abnormalities: in Case 5 there was mild mitral stenosis; in Case 6 there was congenital mitral stenosis of moderate severity; and in Case 7, atresia of the left pulmonary artery. The hæmodynamic data are listed in Table I.

In two of the seven patients with ventricular septal defect the pulmonary blood flow was between two and three times the systemic, the left-to-right shunt being large and the pulmonary artery pressure and resistance normal (Cases 4 and 2). The pulmonary blood flow was proportionally much smaller in the other five with a ventricular septal defect where the pulmonary artery pressure and resistance was considerably raised and the left-to-right shunt appreciably reduced (Cases 3-7). Of the four patients with atrial septal defect there were two (Cases 8 and 9) who had a low pulmonary vascular resistance with a high pulmonary blood flow, and two (Cases 10 and 11) who had a high pulmonary vascular resistance with a low pulmonary blood flow. These patients could be compared with the four patients with patent ductus, two of whom (Cases 12 and 13) had a low pulmonary vascular resistance and a high pulmonary blood flow, and two (Cases 14 and 15) 
TABLE I

Hamodynamic Data on the 15 Patients with Circulatory Shunts

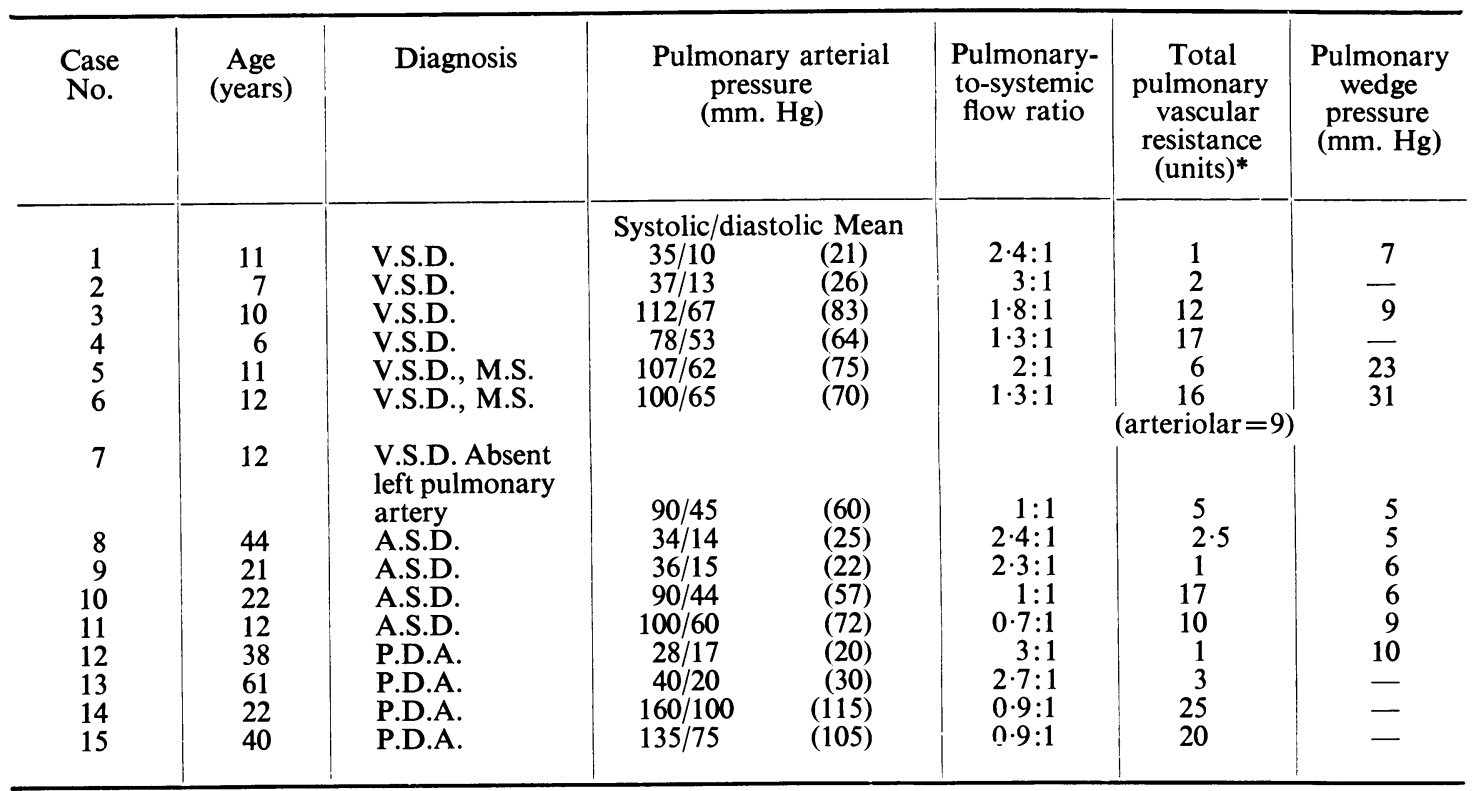

* Total pulmonary vascular resistance $=$ mean pulmonary artery pressure $\mathrm{mm} . \mathrm{Hg} . \div$ Pulmonary blood flow litres per minute.

V.S.D. =Ventricular Septal Defect. A.S.D. $=$ Atrial Septal Defect. P.D.A. $=$ Patent Ductus Arteriosus. M.S. $=$ Mitral Stenosis.

TABLE II

The Clearance Rate of Radioactive Carbon Dioxide from the left Upper Zone and the Right Lower Zone in the 15 Patients and a Comparison of the Size of Shunt Estimated from Routine Dye Curves and the Isotope METHOD

\begin{tabular}{|c|c|c|c|c|c|c|c|}
\hline \multirow[t]{2}{*}{$\begin{array}{l}\text { Case } \\
\text { No. }\end{array}$} & \multirow[t]{2}{*}{ Diagnosis } & \multicolumn{2}{|c|}{$\begin{array}{l}\text { Carbon dioxide clearance } \\
\text { rate } \% / \mathrm{sec} \text {. }\end{array}$} & \multirow[t]{2}{*}{$\begin{array}{l}\text { Ratio: } \\
\text { upper/lower }\end{array}$} & \multirow{2}{*}{$\begin{array}{l}\text { Pulmonary- } \\
\text { to-systemic } \\
\text { flow ratio }\end{array}$} & \multicolumn{2}{|c|}{$\begin{array}{c}\text { Estimated size of left-to- } \\
\text { right shunt }\end{array}$} \\
\hline & & $\begin{array}{l}\text { Left upper } \\
\text { zone }\end{array}$ & $\begin{array}{l}\text { Right lower } \\
\text { zone }\end{array}$ & & & Dye curves & $\begin{array}{c}\text { Radioactive } \\
\text { carbon } \\
\text { dioxide }\end{array}$ \\
\hline $\begin{array}{r}1 \\
2 \\
3 \\
4 \\
5 \\
6 \\
7 \\
8 \\
8 \\
9 \\
10 \\
11 \\
12 \\
13 \\
14 \\
15\end{array}$ & $\begin{array}{l}\text { V.S.D. } \\
\text { V.S.D. } \\
\text { V.S.D. } \\
\text { V.S.D. } \\
\text { V.S.D., M.S. } \\
\text { V.S.D., M.S. } \\
\text { V.S.D. absent left } \\
\text { pulmonary artery } \\
\text { A.S.D. } \\
\text { A.S.D. } \\
\text { A.S.D. } \\
\text { A.S.D. } \\
\text { P.D.A. } \\
\text { P.D.A. } \\
\text { P.D.A. } \\
\text { P.D.A. }\end{array}$ & $\begin{array}{r}34 \cdot 1 \\
45 \cdot 6 \\
27 \cdot 2 \\
25 \cdot 1 \\
27 \cdot 1 \\
29 \cdot 5 \\
\\
5 \cdot 0 \\
38 \cdot 4 \\
40 \cdot 1 \\
8 \cdot 4 \\
21 \cdot 8 \\
25 \cdot 0 \\
36 \cdot 0 \\
7 \cdot 1 \\
6 \cdot 6\end{array}$ & $\begin{array}{r}27 \cdot 1 \\
62 \cdot 4 \\
26 \cdot 1 \\
23 \cdot 1 \\
26 \cdot 6 \\
7 \cdot 3 \\
38 \cdot 0 \\
36 \cdot 8 \\
62 \cdot 4 \\
11 \cdot 1 \\
26 \cdot 5 \\
52 \cdot 8 \\
45 \cdot 6 \\
9 \cdot 9 \\
7 \cdot 7\end{array}$ & $\begin{array}{l}1.26 \\
0.73 \\
1.04 \\
1.09 \\
1.02 \\
4.04 \\
\\
-\overline{1} .04 \\
0.65 \\
0.76 \\
0.82 \\
0.47 \\
0.78 \\
0.72 \\
0.86\end{array}$ & $\begin{array}{r}2 \cdot 4: 1 \\
3: 1 \\
1 \cdot 8: 1 \\
1 \cdot 3: 1 \\
2: 1 \\
1 \cdot 3: 1 \\
1: 1 \\
2 \cdot 4: 1 \\
2 \cdot 3: 1 \\
1: 1 \\
0 \cdot 7: 1 \\
3: 1 \\
2 \cdot 7: 1 \\
0 \cdot 9: 1 \\
0 \cdot 9: 1\end{array}$ & $\begin{array}{r}+ \\
++ \\
++ \\
++ \\
++ \\
+ \\
++ \\
++ \\
++ \\
++ \\
++ \\
=\end{array}$ & $\begin{array}{r}++ \\
++ \\
++ \\
+ \\
+ \\
+ \\
+ \\
++ \\
++ \\
+++ \\
++ \\
++ \\
++ \\
++\end{array}$ \\
\hline
\end{tabular}

In patient No. 7 both counters were placed over the upper zone.

Dye curves were not performed in Cases 4, 10, and 13. In Case 11 a bidirectional shunt was demonstrated on the blood samples and the dye curves.

V.S.D.= Ventricular Septal Defect. A.S.D.=Atrial Septal Defect. P.D.A.=Patent Ductus Arteriosus. M.S.= Mitral Stenosis. 
a high pulmonary vascular resistance and a low pulmonary blood flow. Thus the cases selected presented a wide spectrum of the pulmonary blood flow and resistance commonly produced by shunts in the heart and great vessels.

\section{RESULTS}

The carbon dioxide clearance data are summarized in Table II. The patients fall into four groups according to the diagnosis.

\section{Ventricular Septal Defect without associated congenital abnormalities (Patients 1-4)}

In the first two patients with ventricular septal defect, in whom the pulmonary arterial pressure was normal, the large pulmonary blood flow was reflected in high carbon dioxide clearance rates at both upper and lower zones with evidence of a large left-to-right shunt in the isotope recirculation peaks (see description of patient 1 , below). The second pair in this group had a pulmonary artery pressure approaching systemic level and a smaller left-to-right shunt. The carbon dioxide clearance rates at upper and lower zones were lower than in the first pair and were similar in both zones. The recirculation peaks indicating left-to-right shunts were also smaller.

Case Report. Patient No. 1, a boy aged 11, was asymptomatic. The clinical features were those of an uncomplicated ventricular septal defect with a large left-to-right shunt. The data obtained at cardiac catheterization supported this diagnosis. The pulmonary artery pressure was $35 / 10 \mathrm{~mm}$. $\mathrm{Hg}$, the ratio of pulmonary to systemic blood flow $2 \cdot 4$ to 1 , and the pulmonary arteriolar resistance 1 unit. The clearance curves for carbon dioxide were obtained from the level of the left second rib, and three inches below it over the right lung.

The carbon dioxide curves show a rapid upward deflection at the first arrow indicating the point of inspiration. During the period of breath-holding, between the two arrows, there is initially a rapid downstroke

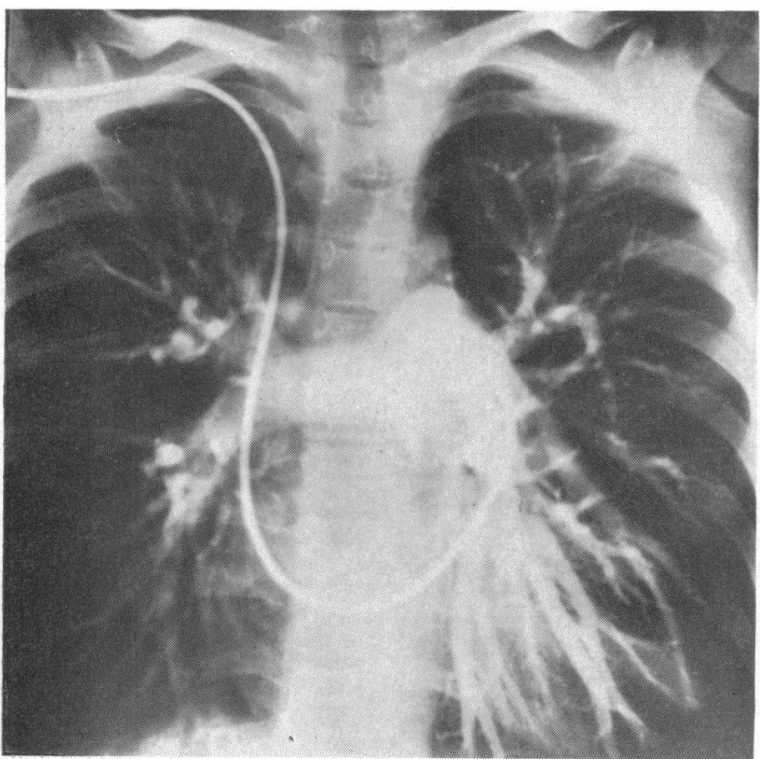

FIG. 1.-Pulmonary arteriogram of patient 1 who had an uncomplicated ventricular septal defect with low pulmonary vascular resistance. The pulmonary arteries are all dilated.

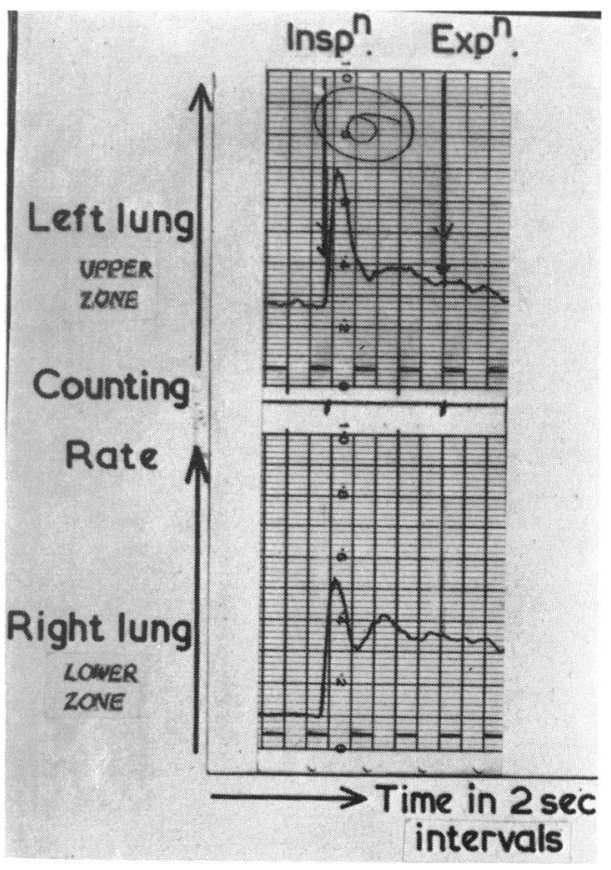

Fig. 2.-Carbon dioxide curves recorded from the level of the left second rib (upper zone) and 3 inches $(7.5 \mathrm{~cm}$.) lower down (lower zone) over the right lung in patient 1 . Similar clearance rates are shown from both zones (see text). 
as the labelled blood is swept from the counting field by the high flow. After two seconds labelled blood returns to the field from the right heart having been shunted through the ventricular septal defect. The return of the labelled blood causes a secondary upward deflection in both recorders; afterwards the patient resumed normal breathing. The high flow in both upper and lower zones shown by the isotopes can be related to the generalized dilation of the pulmonary vessels shown in the pulmonary arteriogram (Fig 1). In this patient the carbon dioxide clearance rate was $34 \cdot 1$ per cent per second at the left upper zone and $27 \cdot 1$ per cent per second at the right lower zone, the ratio of upper zone to lower zone clearance rates being 1.26 (Fig. 2).

\section{Ventricular Septal Defect with Associated Congenital Lesions (Patients 5-7)}

The first two patients in this group were thought on clinical grounds to have associated mitral stenosis. The first, patient 5, had findings at cardiac catheterization compatible with a ventricular septal defect with pulmonary hypertension, although the pulmonary "wedge" pressure of $23 \mathrm{~mm}$. Hg was unusually high for an uncomplicated ventricular septal defect. The radioactive carbon dioxide clearance curves showed similar clearance rates at upper and lower zones, $27 \cdot 1$ and 26.6 per cent per second respectively. When the ventricular septal defect was closed during cardio-pulmonary bypass only mild mitral obstruction was found, the diastolic gradient between left atrium and left ventricle being $7 \mathrm{~mm}$. $\mathrm{Hg}$.

The second patient with ventricular septal defect and mitral stenosis showed a very different picture.

Case Report. Patient No. 6, a boy aged 11, had been troubled since infancy by frequent chest infections. He had always been short of breath, became slightly cyanosed on effort, and recently both symptoms had become more prominent. There was no history of squatting, syncopal attacks, or rheumatic fever. The physical signs suggested a ventricular septal defect with pulmonary hypertension and mitral stenosis which

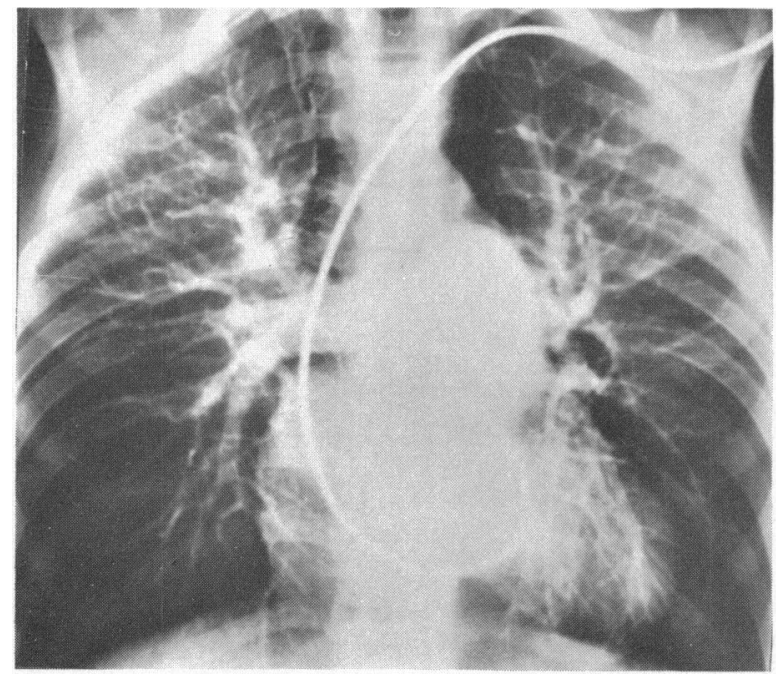

FIG. 3.-Right ventricular angiogram of patient 6 , with congenital mitral stenosis and a ventricular septal defect. There is selective narrowing of the arteries of the lower zones.

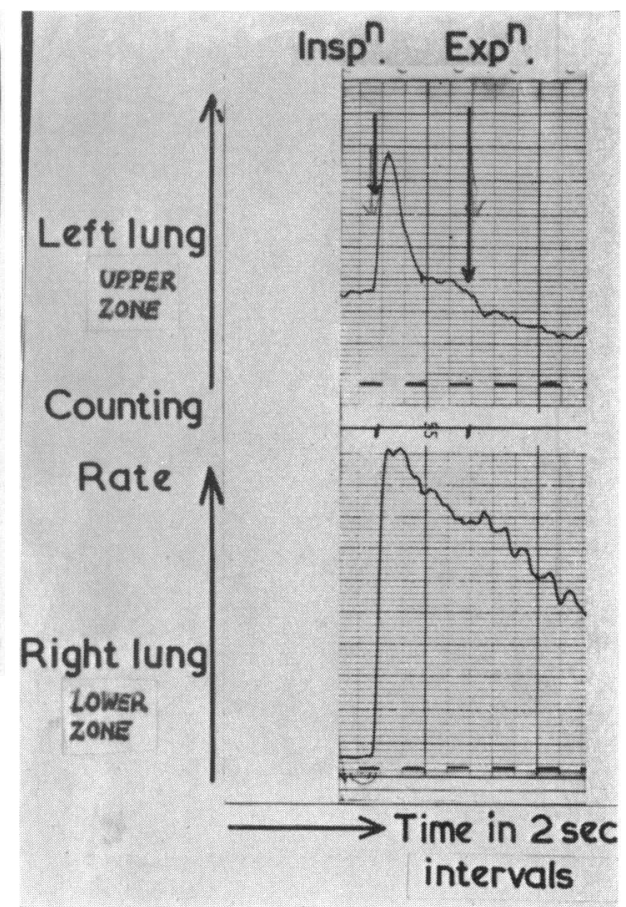

FIG. 4.-Carbon dioxide clearance curves recorded from the level of the left second rib (upper zone) and $3 \frac{1}{2}$ inches $(9 \mathrm{~cm}$.) lower down over the right lung (lower zone) in patient 6 , showing much smaller clearance rate from the lower than the upper zone (see text). 
was presumed to be congenital. In addition to a short systolic murmur audible at the left sternal edge, which was attributed to the ventricular septal defect, there was a presystolic thrill and a full length mid-diastolic murmur in the mitral area preceded by an opening snap. Cardiac catheterization showed that there was a small left-to-right shunt at ventricular level (the ratio of pulmonary to systemic blood flow being 1.3 to 1), and a small right-to-left shunt in addition. The pulmonary artery pressure was $100 / 65 \mathrm{~mm} . \mathrm{Hg}$ and the pulmonary "wedge" pressure was also grossly raised at $31 \mathrm{~mm}$. $\mathrm{Hg}$. An angiogram from the right ventricle demonstrated a high ventricular defect and also showed selective narrowing of the basal pulmonary arteries and veins (Fig. 3), the pattern commonly seen in severe mitral stenosis (Doyle et al., 1957). At operation by Mr. W. P. Cleland an infracristal defect $2.5 \mathrm{~cm}$. in diameter was repaired, using a Teflon patch. The mitral valve consisted of a diaphragm perforated by a round hole $1 \mathrm{~cm}$. in diameter.

The clearance curves for carbon dioxide obtained from the left upper zone and right lower zone are shown in Fig. 4. The carbon dioxide clearance rate was 29 per cent per second at the left upper zone and only 7 per cent per second at the right lower zone. The ratio of upper to lower zone clearance rates was 4.0:1 in contrast to the four patients with uncomplicated ventricular septal defects who had a mean ratio of upper to lower zone clearance rates of 1.03. This suggests that much of the pulmonary vascular disorder was due to the mitral stenosis. Thus there was good general agreement between the angiographic and isotope results.

The final patient in this group was also of interest for he was found to have an absent left pulmonary artery.

Case Report. Patient No. 7, a boy aged 13, had been known to have a heart lesion in infancy. His exercise capacity had been moderately limited all his life and he was unable to play competitive games. The clinical features were those of a ventricular septal defect with considerable pulmonary hypertension but still with a left-to-right shunt, a short mitral diastolic flow murmur being audible. The radiograph revealed an enlarged right pulmonary artery with pulmonary plethora on that side, but the left pulmonary artery could not be seen. At catheterization the pressure in the right pulmonary artery was $90 / 45 \mathrm{~mm}$. $\mathrm{Hg}$. The

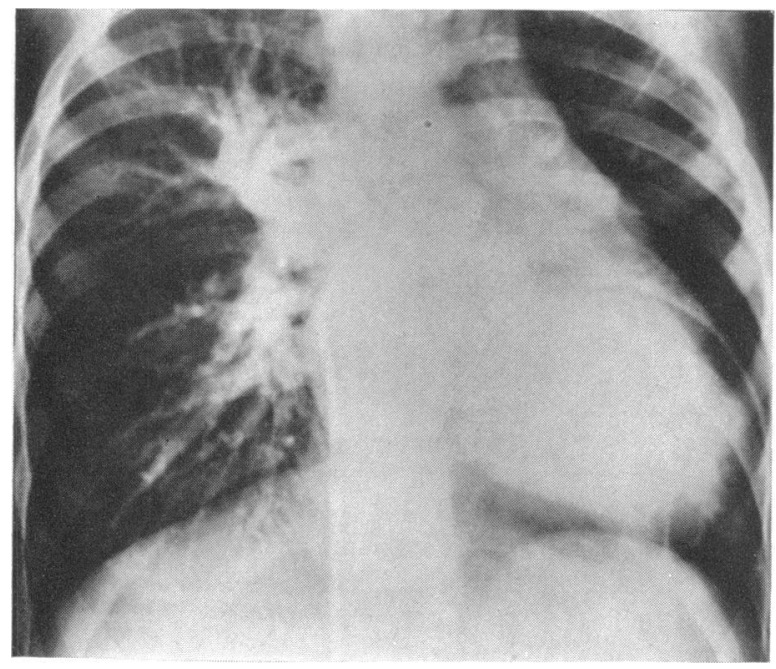

FIG. 5.-Right ventricular angiogram of patient 7 , with ventricular septal defect and absence of the left pulmonary artery. The right pulmonary artery and its branches are greatly enlarged, but the left pulmonary artery is not visualized.

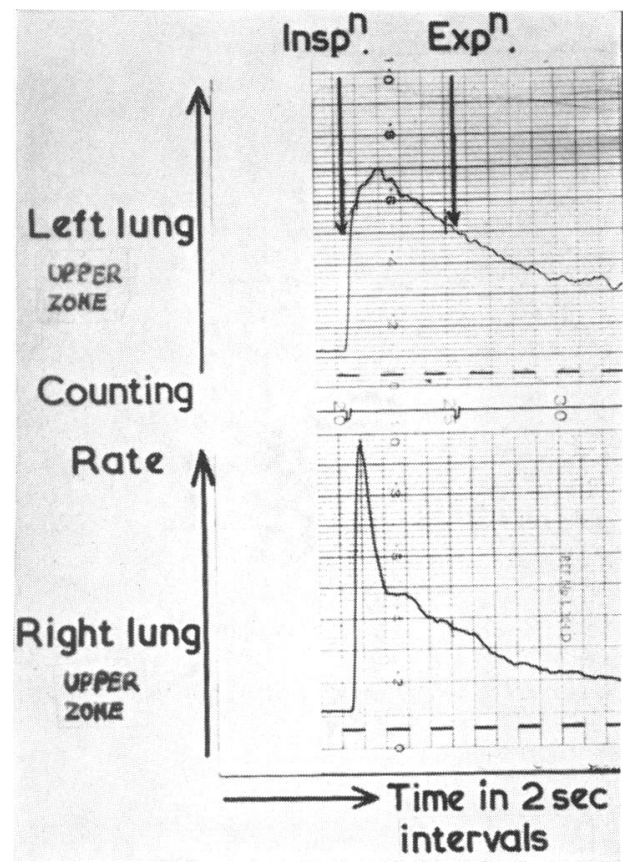

FIG. 6.-Carbon dioxide clearance curves in patient 7 from the level of the second rib 3 inches $(7.5 \mathrm{~cm}$.) from the mid-line over each lung showing a higher clearance from the right lung than from the left (see text). 
left branch was not entered, and an angiogram confirmed that there was atresia of the left pulmonary artery (Fig. 5). There was no definite evidence of a left-to-right shunt on the blood samples taken at catheterization though dye dilution curves did indicate that there was one present. The arterial saturation was normal.

Carbon dioxide clearance curves showed a clearance rate of 5.0 per cent per second from the left second space and 38.0 per cent per second from the right second space (Fig. 6). The clearance curve on the left side showed a slower rise to peak. The reason for this is not fully understood but may indicate some circulation of labelled blood via the bronchial arteries. There was a small left-to-right shunt shown on the isotope traces.

\section{Atrial Septal Defect (Patients 8 to 11)}

The first pair of these four patients had the typical signs of atrial septal defect with low pulmonary artery pressure and high pulmonary blood flow. The ratios of pulmonary to systemic blood flows were $2 \cdot 3$ and 2.4:1 respectively and the carbon dioxide clearance curves in both patients showed a very high clearance rate at apex and base. The curves were similar in all respects to those found in ventricular septal defect with high pulmonary blood flow demonstrated in Fig. 1. The indicator dye dilution and isotope tracings showed large left-to-right shunts. The second pair of patients (No. 10 and 11) had clinical signs of atrial septal defect with pulmonary hypertension and a right-to-left shunt. At cardiac catheterization the pulmonary artery pressures were $90 / 44$ and $100 / 60 \mathrm{~mm}$. $\mathrm{Hg}$ respectively, with ratios of pulmonary to systemic blood flow of $1: 1$ and $0 \cdot 7: 1$ respectively. The carbon dioxide clearance rates were much lower than in the patients with a high pulmonary blood flow. Both indicator dye dilution and isotope curves showed a small left-toright shunt in patient No. 11, and in addition a right-to-left shunt was shown by the dye dilution curves. Patient No. 10 showed no shunt on the isotope curves, and dye dilution curves were not performed.

Patent Ductus. There were four patients (No. 12, 13,14,15) with this diagnosis, the first two having a low pulmonary artery pressure and high pulmonary blood flow, while the second pair had pulmonary artery pressure at systemic level and a ratio of pulmonary to systemic blood flow of 0.9:1. The patients

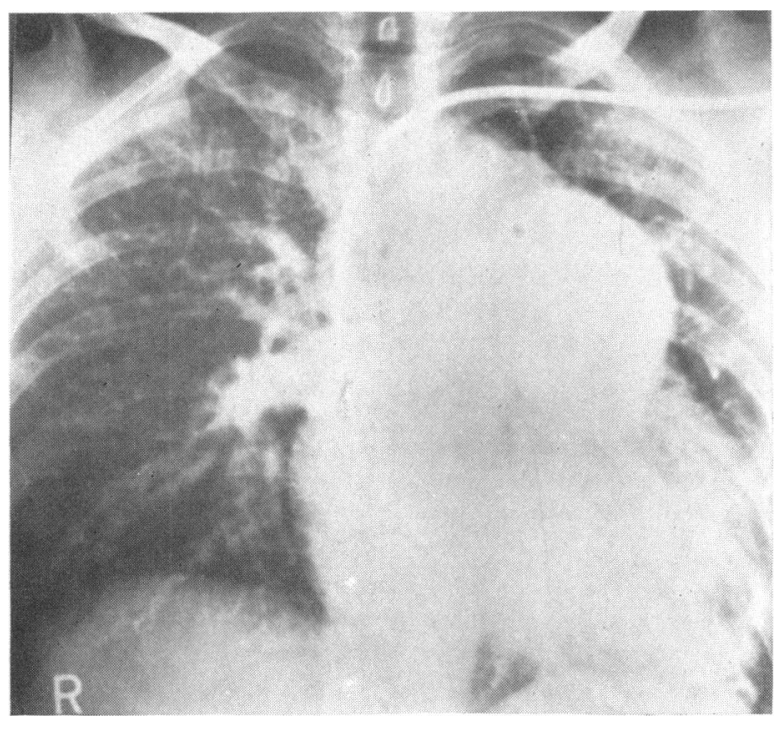

FIG. 7.-Angiocardiogram of patient 15 with patent ductus arteriosus and severe pulmonary hypertension. There is great dilatation of the main pulmonary artery with tortuosity and narrowing of the peripheral branches.

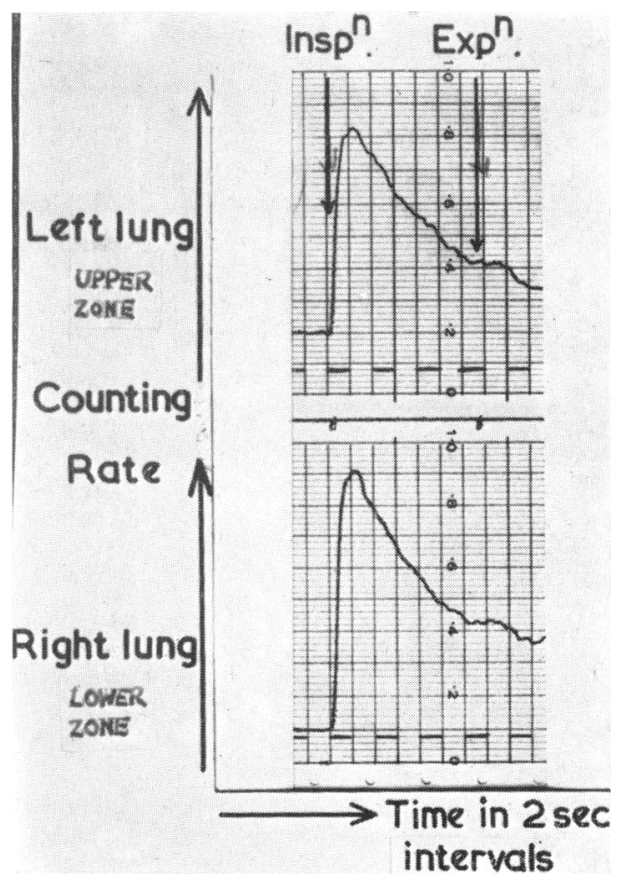

FIG. 8.-Carbon dioxide clearance curves in patient 15 from the level of the left second rib (upper zone) and 4 inches $(10 \mathrm{~cm}$.) lower over the right lung (lower zone), showing equal clearance rates (see text). 


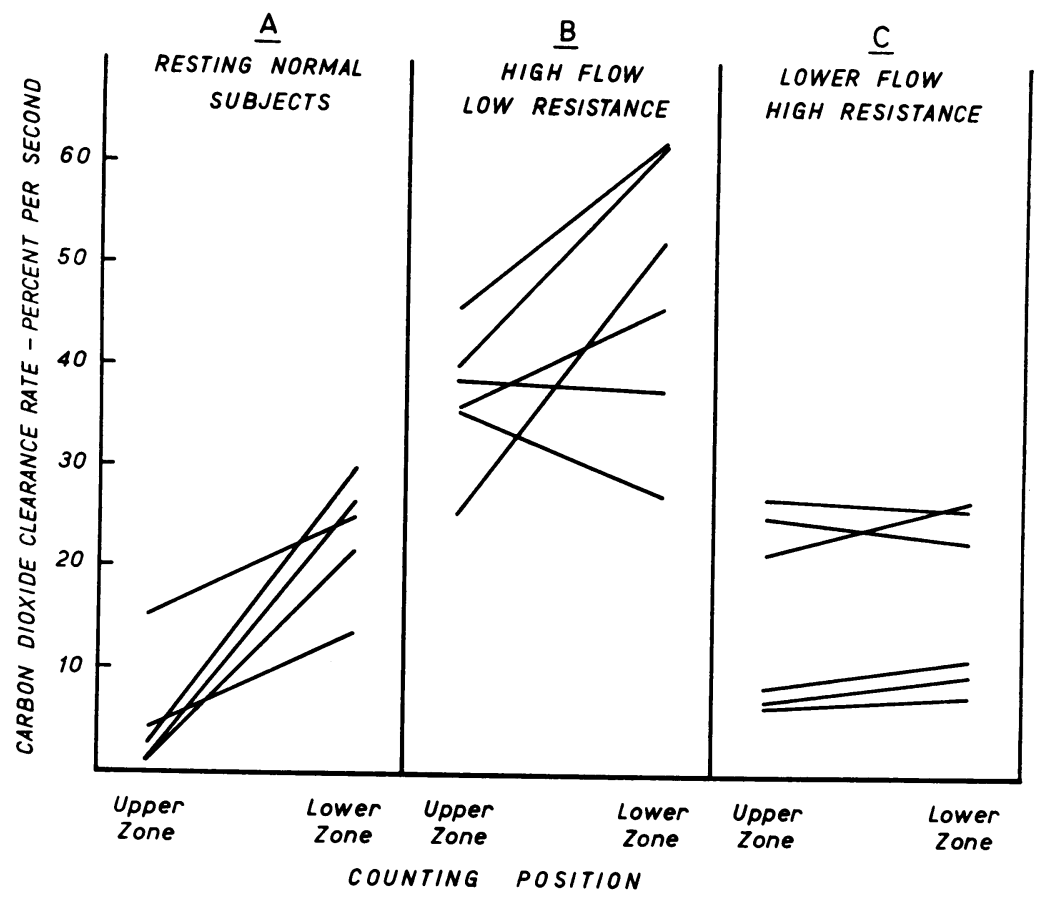

Fig. 9.-Carbon dioxide clearance rates from upper and lower zones in (A) 5 normal subjects, (B) 6 patients with left-to-right shunt and low pulmonary vascular resistance, and (C) 6 patients with smaller left-to-right shunt and high pulmonary vascular resistance (see text).

with high pulmonary blood flow had high carbon dioxide clearance rates at both apex and base and showed large recirculation peaks. The findings were similar in every way to those in patients with septal defects and high pulmonary flow. The two patients who had patent ductus and pulmonary hypertension had very much slower carbon dioxide clearance rates at both upper and lower zones and there was no evidence of a left-to-right shunt.

Case Report. Patient No. 15 was a 40-year-old married woman who had been told in childhood that she had a heart lesion. Nevertheless she had lived an active life and had been free of symptoms during two pregnancies, 13 and 11 years previously. Recently she had become dyspnoeic on moderate exertion with ankle swelling in the evening. Clinically there was slight cyanosis of her legs but not of her arms, and there were signs of severe pulmonary hypertension with pulmonary regurgitation. Further investigations supported the diagnosis of patent ductus arteriosus with shunt reversal. The pulmonary artery and brachial artery mean pressures were equal $(105 \mathrm{~mm}$. $\mathrm{Hg})$. The brachial artery sample was 96 per cent saturated, and that of the femoral artery 85 per cent saturated. A dye dilution curve obtained from a pulmonary artery injection, and an angiocardiogram, both demonstrated that the right-to-left shunt was at pulmonary artery level (Fig. 7 and 8).

The carbon dioxide clearance rate was 6.6 per cent per second in the left upper zone and 7.7 per cent per second in the right lower zone (Fig. 8). There was no evidence of a left-to-right shunt on either the carbon dioxide clearance curves or the dye curves.

The Pattern of Carbon Dioxide Clearance with the Different Lesions. A consideration of the patients with ventricular septal defect, atrial septal defect, and patent ductus uncomplicated by other congenital lesions shows that they fall into two distinct categories, those with and those without severely raised pulmonary vascular resistance. When the patients are divided into two groups according to the pulmonary vascular resistance (above and below 3 units respectively) the difference in the carbon dioxide clearance rates between these two groups is striking. Although there was a big difference in the pulmonary blood flow in the absolute isotope clearance rates between the groups (Fig. 9) there was no significant difference 


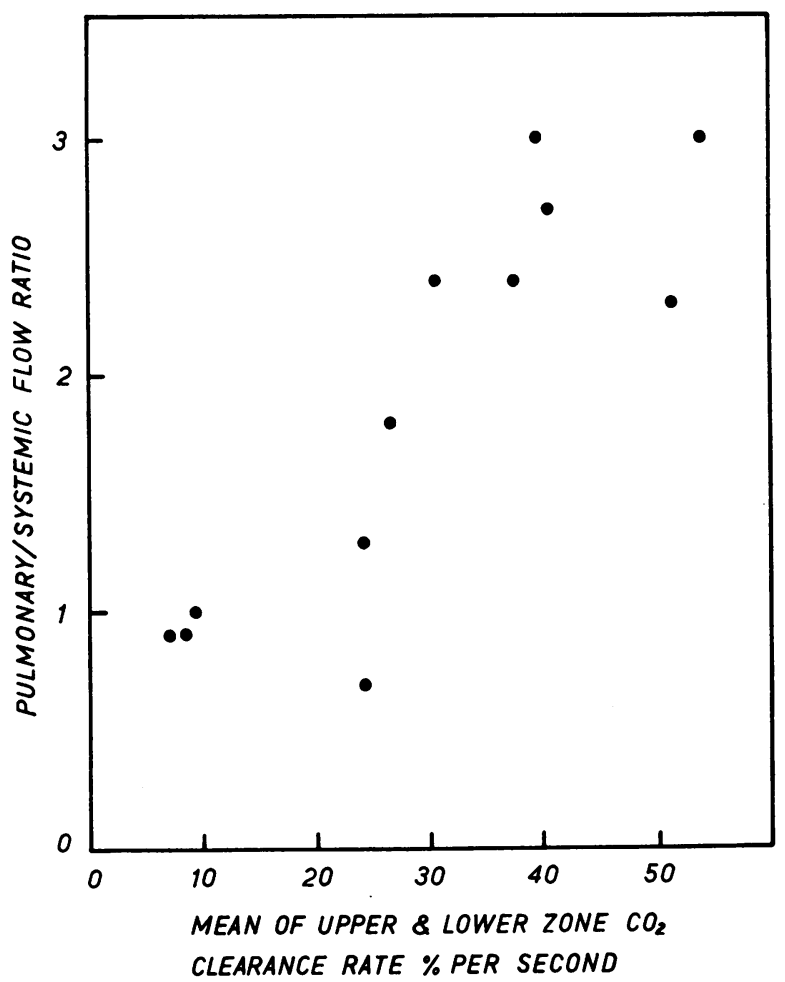

FIG. 10.-The ratio of pulmonary to systemic blood flow plotted against the mean carbon dioxide clearance rates from upper and lower zones of the lungs in 12 patients with uncomplicated septal defects, showing that the clearance rates vary directly with the pulmonary blood flow.

in the mean upper/lower zone ratios which were 0.80 and 0.88 respectively in the two groups. The overall reduction in carbon dioxide clearance in the patients with pulmonary hypertension resulted from their low pulmonary flow. This is best shown by comparing the ratio of pulmonary to systemic blood flow with the mean of the upper and lower zone clearance rates (Fig. 10). The ratio of pulmonary to systemic flow is more satisfactory for comparative purposes than the actual values for pulmonary flow because the group consisted of both children and adults.

The isotope traces were sensitive in the detection of left-to-right shunts. An attempt was made to grade the magnitude of the shunt as detected first by the dye dilution curve, and then by the carbon dioxide clearance curves, and to compare these findings with the size of the shunt determined by the Fick principle. From a study of the form of the dye dilution curve and the shape and relative size of the recirculation hump on the isotope trace, the left-to-right shunt was estimated by each method as being either small $(+)$, moderate $(++)$, or large $(+++)$. The results were comparable by both methods (Table II).

\section{Discussion}

The first objective of this investigation was to compare the blood flow in the upper and lower zones of the lung under a variety of conditions of pressure and flow. For this purpose we have used the ratio of the carbon dioxide clearance rates measured simultaneously in the upper and lower zones. This ratio in adult patients can be compared directly with the normal values, but in the younger patients comparisons must be made with caution because we have no comparable normal data.

The value of carbon dioxide clearance rate in a given region of the lung is a measure of the blood flow per unit of ventilated lung volume. All measurements were made from the left upper zone and 
the right lower zone, as radioactive blood draining from the lung accumulated in the heart and was found to interfere with the clearance curves from the left lower zone in some patients with enlarged hearts. The comparisons that we have made always refer to these areas. If there were a substantial difference in flow between the left and right lung, as has been suggested for patients with atrial septal defect (Fleming, 1959), this would affect the accuracy of the comparison.

The ratio of upper to lower zone clearance rates was $0 \cdot 2: 1$ in the five normal subjects; in the patients with high pulmonary blood flow it was 0.80 , and in patients with pulmonary hypertension 0.88 . The difference in the mean ratio between both groups of patients from the normal subjects is highly significant $(P<0.01)$ but between the two groups of patients the difference is not significant. Both groups of patients had a much higher blood flow through the upper zone than was found in normals. The explanation for this difference may not be the same in the two groups of patients.

The first group, with high pulmonary blood flow, can be compared with exercising normal subjects. Observations made in normal subjects immediately after exercise have shown that there is an increase in both upper and lower zone flows, but that the increase in the upper zone flow is relatively greater, as the ratio of upper to lower zone clearance rates increased from the resting value of $0 \cdot 2: 1$ to $0 \cdot 6: 1$ (West and Dollery, 1960). The normal subjects performed only a moderate amount of exercise, and the carbon dioxide clearance rates reached were lower than those found in the patients with large left-to-right shunts.

In these patients the increase in flow in both zones with a relatively greater increase in the upper zone may be a direct result of the higher flow, and an exaggeration of a similar trend found in normal subjects when the pulmonary blood flow is increased on moderate exercise.

The results obtained from patients with extreme pulmonary hypertension need a different explanation as the pulmonary blood flow was normal or low. It is probable that the increase in the pulmonary artery pressure was itself responsible for the more even perfusion of the lung. There is good evidence that the normal low perfusion at the upper zone is a direct result of gravity, for the perfusion in upper and lower zones becomes equal in the supine position (West and Dollery, 1960). The high pulmonary artery pressure in these patients would make the influence of gravity much less. Patients with severe pulmonary hypertension should have a more uniform arteriolar pressure throughout the lung and it is possibly for this reason that flow in the upper and lower zones becomes nearly equal.

None of the patients with uncomplicated defects with or without pulmonary hypertension showed the steep inversion of the upper/lower zone clearance rate ratio which has been observed in patients with severe mitral stenosis. It is of the greatest interest that the only patient in the present series who showed this flow pattern was found at operation to have congenital mitral stenosis. This finding with the evidence already available from patients with mitral stenosis and left ventricular failure provides further evidence that changes in pulmonary venous pressure, and not in arterial pressure, play a fundamental part in determining the great reductions of lower zone blood flow found in some patients with heart disease.

The values of carbon dioxide clearance rate correlated reasonably well with measurements of the ratio of pulmonary to systemic flow calculated by the Fick method. This was to be expected because both measurements depend upon blood flow.

Experience with the technique using labelled carbon dioxide suggest that it is as sensitive in the detection of left-to-right shunts as the indicator dye dilution method using Coomassie blue dye, and possibly more sensitive than the standard methods of measuring the oxygen saturation of the blood. A left-to-right shunt was present in 12 of the 15 patients but was small in three of them. In each case the shunt was revealed by the isotope method. In patient 7 a shunt was not demonstrated by measuring the blood oxygen saturation at two separate cardiac catheterizations, although a small shunt was clearly shown by both the dye and isotope methods. In patient 6 the ratio of pulmonary to systemic blood flow was $1 \cdot 3: 1$, and in patient 11 the shunt was predominantly rightto-left; in both these patients small left-to-right shunts were detected by all three methods.

Quantitative estimates of left-to-right shunts from routine dye dilution curves are inaccurate 
although they can be measured by a more elaborate dye technique (Wood et al., 1958). To compare the dye and isotope methods on a semi-quantitative basis the curves were graded into one of three sizes (small, moderate, or large) and related to the shunt flow measured by the Fick principle (Table II). The correlation with the calculated shunt flow was reasonably good with both the isotope and the dye methods.

Another radioactive gas, krypton 85 , has been used in the detection of circulatory shunts, either inhaled into the lungs during right heart catheterization and detected in the blood, or after injection in solution into the right side of the heart and detected by early appearance of the labelled gas in the arterial circulation (Sanders and Morrow, 1958; Braunwald et al., 1959).

All these methods may permit the localization of a left-to-right shunt and a semi-quantitative estimation of the flow through it. However, the technique with labelled carbon dioxide is simpler, apparently reliable, without danger or discomfort; and it makes possible the detection of left-toright shunts under more physiological conditions.

\section{SUMMARY}

Pulmonary blood flow to the upper and lower zones of the lungs in a group of patients with circulatory shunts were compared using radioactive carbon dioxide. The clearance rate of carbon dioxide correlated directly with the ratio of pulmonary to systemic blood flow. Six patients with high pulmonary flow and normal pulmonary pressure, and another six patients with normal pulmonary flow and high pulmonary pressure all had a higher perfusion in the upper zone than normal subjects, suggesting that either high pulmonary blood flow or high pulmonary arterial pressure can open the upper zone vessels.

Only one patient (who had congenital mitral stenosis in addition to a ventricular septal defect) showed a much higher flow at the apex than the base, the pattern of flow resembling the pattern that occurs in severe mitral stenosis.

The clearance curves of carbon dioxide promise to be a sensitive method of detecting left-toright shunts.

We thank Mr. P. Buckingham and Mr. G. Forse for valuable assistance and the staff of the Medical Research Council Radio Therapeutic Research Unit for the use of the Cyclotron. We are also indebted to Professor R. E. Steiner for radiological assistance, and to Dr. A. Hollman for help with cardiac catheterizations.

\section{REFERENCES}

West, J. B., and Dollery, C. T. (1960). J. appl. Physiol., 15, 405.

Dollery, C. T., and West, J. B. (1960). Circulation Res., 8, 705.

- _ (1960 a). J. Physiol., 154, 12 pp.

$\overline{\text { West }}, \overline{\mathrm{J}}$ (in preparation).

West, J. B., Dollery, C. T., and Hugh-Jones, P. J. clin. Invest. (in press).

Doyle, A. E., Goodwin, J. F., Harrison, C. V., and Steiner, R. E. (1957). $\quad$ Brit. Heart J., 19, 353.

Fleming, H. A. (1959). Circulation, 19, 856.

Wood, E. H., Swan, H. J. C., and Marshall, H. W. (1958). Proc. Mayo Clin., 33, 536.

Sanders, R. J., and Morrow, A. G. (1958). Bull Johns Hopk. Hosp., 103, 27.

Braunwald, E., Long, R. T. L., and Morrow, A. G. (1959). J. clin. Invest., 38, 990. 